\title{
A study of refining conditions for the efficient smelting of copper compounds by using automated multivariate statistical phase analysis of EDS spectral imaging data obtained from a silicon drift detector
}

SDD-EDS と多変量イメージ解析技術を用いた銅複合化合物からの効果的な製錬条件の検討

\author{
Mitsuhiro WADA \\ Corporate R\&D Center, Mitsui Mining \& Smelting Co., Ltd., 1333-2 Haraichi, Ageo-shi, Saitama \\ 362-0021 \\ TEL: x81-48-775-3211 FAX:x81-48-775-6373 e-mail:m_wada@mitsui-kinzoku.cp.jp
}

\author{
Yukio KAWASHIMO \\ Metals, Minerals \& Environmental Engineering Sector, Mitsui Mining \& Smelting Co., Ltd., 1-11-1 \\ Osaki, Shinagawa-ku, Tokyo 141-8584
}

TEL: $x 81-3-5437-8060 \quad$ FAX: $x 81-3-5437-8073$

(Received 25 January, 2011 Accepted 27 February, 2011)

Copper-bearing dross generated in lead metal smelting operations is composed of very complex compounds which include $\mathrm{Pb}, \mathrm{Sn}$ and $\mathrm{Sb}$. The presence of these elements makes the dross difficult to process. The copper compounds also include valuable metals and rare earth elements, therefore an efficient refining technology is required. In previous works, we have shown that evaluating the dross phases by using both fast Silicon drift detector technology (Thermo Scientific UltraDry) and multivariate statistical component analysis (Thermo Scientific COMPASS) is very effective. In this work, we investigated the refining heat treatment conditions in the process of the copper-bearing dross. The results of the COMPASS phase analysis showed that a $\mathrm{Cu}-\mathrm{Sn}$ alloy was the main copper-bearing phase generated in the dross when small amounts of oxygen were introduced during the heat treatment process. Conversely, under high oxygen conditions during the process $\mathrm{CuO}$ is generated as the principal copper-bearing dross component. The leaching rate of $\mathrm{Cu}$ was about $50 \%$ after sulfuric acid leaching for the unprocessed dross. The leaching rate of $\mathrm{Cu}$ increased to more than $95 \%$ for the processed dross in which the principal component was $\mathrm{CuO}$. Using these analysis results, we were able to rapidly and accurately determine the efficiency improvement of the copper refining process.

Keywords : Cu compound, SDD-EDX, Multivariate statistical analysis, Ferrous metal

\section{INTRODUCTION}

一般的に銅は多くの化合物を形成することが知られて いる。特に銅を含むドロスは $\mathrm{Cu}$ 以外にも $\mathrm{Sn}$ や $\mathrm{Pb}$ をは じめ、 $\mathrm{S}, \mathrm{Sb}, \mathrm{As}$ 等と共に非常に複雑な混合化合物を作る ことが知られている。非鉄金属製鍊では、 $\mathrm{Cu}$ や $\mathrm{Zn} 、 \mathrm{~Pb}$ を主とする非常に複雑な化合物から、各元素の製錬を行
つていが、1-3ドロスの殆どは一般的には処理が難しかっ た。 ${ }^{4} し か し$ 近年では、これらの銅含有複合化合物には、 銅以外にもレアアースなどをはじめとする有価金属が複 数含まれており、効率的な製錬技術が求められている。 また従来活用していなかった資源からの回收技術の向上 は、省資源化や環境負荷の低減化に大きく寄与寸る技術 
である。

従来処理が難しかった含銅ドロスについて、銅をはじ めとする有価金属を効率的に、容易に、かつ短時間で回 収可能な手段を得るためには、処理工程における銅など の存在状態を把握し、反応機構を解明することが重要で ある。

我々はこれまでの銅含有複合化合物の研究における複 雑な相分布状況の把握について、Silicon Drift Detector （SDD）型の高速度エネルギー分散 X線分析（EDS）検 出器と多変量イメージ解析技術を組み合わせた評価解析 技術が、従来のX線回折法（XRD）とX線マイクロプロ ーブ顕微鏡（EPMA）評価に比べて、同等の評価水準な がらも圧倒的に迅速な評価が可能であることを実証して きた。 5

本研究では、銅の高い硫酸浸出率を実現することを目 的とし、SDD-EDS と多変量イメージ解析技術を組み合わ せた評価技術を用いて、気相酸化熱処理工程時における 酸素供給量が及ぼす処理後の銅の存在状態を把握するこ とで、含銅ドロスの反応機構を検討し、硫酸浸出におけ る最も効率的な前処理条件を検討したので報告する。

\section{EXPERIMENTAL DETAILS}

本報告では、今回は鉛製錬後に生成される銅含有複合 化合物（含銅ドロス）を試料とし、熱処理時に酸素供給 量を変化させた際の相解析を実施した。試料は $100 \mathrm{~kg}$ を ドラム炉に供給し、 $600^{\circ} \mathrm{C}$ で 5 時間かけて気相酸化を行っ た。気相酸化装置には大気導入口が有り、熱処理時に炉 へ導入する大気の供給量をバルブの開閉にて調整できる。 なお、今回はバルブの開閉を、0\%（全閉）、10\%、30\% および 60\%にて熱処理を実施した。

原料試料となる含有ドロスおよび各酸化条件にて熱処 理を行った後の各試料の評価については、以下の通り実 施した。走査電子顕微鏡（SEM）-EDS にて断面の組織 解析を実施した。SEM は Carl-Zeiss 社製の電界放出型走 査電子顕微鏡（FE-SEM） ULTRA 55、EDS はサーモフィ ッシャーサイエンティフィック社製 SDD 型検出器 Ultra Dry を用いてマッピング評価した。EDS 元素分布につい ては、各元素の存在分布を正しく評価するため、 ${ }^{5}$ ピーク 分離 (定量) マッピングを用いて評価した。そして試料 内に存在し得る相の存在と分布は、EDS スペクトルの多 変量イメージ解析ソフトウェア (サーモフィッシャーサ イエンティフィック社製 COMPASS）を用いて、測定同 時多変量解析による自動相分離解析から明らかにした。 加えて各相の化学組成比は、その相分布強度の高い領域 から抽出した EDS スペクトルからスタンダードレス定
量分析によって求めた。なお EDS 評価は、当該粉末試料 を樹脂包埋し、研磨後 C コーティングを行ったものにつ いて実施した。評価視野は、金属顕微鏡および SEM-EDS ともに、 $230 \times 180 \mu \mathrm{m}$ 四方を測定した。EDS 測定は、加 速電圧 $12 \mathrm{kV}$ にて、1 視野あたり 30 分間の積算測定を実 施した。

各試料から $\mathrm{Cu}$ を回収するため、今回は硫酸による浸 出を行った。各処理後の含銅ドロス $200 \mathrm{~g}$ と、 $1.5 \mathrm{~mol} / \mathrm{l}$ の希硫酸水溶液 $2 l$ とを混合してスラリーとなし、60 $\mathrm{C}$ に て 3 時間攪汼した。次にスラリーを固液分離し、濾液中 に含まれている $\mathrm{Cu}$ の量を誘導結合型プラズマ法(ICP)に よって測定した。原料試料中に含まれる $\mathrm{Cu}$ の割合に対 して、この濾液中に含まれている $\mathrm{Cu}$ の割合を浸出率と して求めた。

\section{RESULTS}

まずはじめに、本研究の原料とした含銅ドロスの評価 結果を示す。Fig.1-1 に反射電子像、Fig.1-2 に Cuのピー ク分離マップを示す。自動相分離解析の結果、原料試料 については、包埋樹脂を含め 8 相が検出された。そのう ち銅を主成分として含む相については、 $\mathrm{Cu}_{3} \mathrm{Sn}$ 相と $\mathrm{Cu}_{3} \mathrm{As}$ 相の 2 相検出され、それぞれ Fig.1-3-a)および b)の様に分 布していることが解った。なお、 $\mathrm{Cu}_{3} \mathrm{Sn}$ と結合相として 存在していたのは、金属 $\mathrm{Pb}$ 相であった。

原料の含銅ドロスの $\mathrm{Cu}$ の主成分が $\mathrm{Cu}_{3} \mathrm{Sn}$ であること がわかったので、酸化反応について下記のとおり推察す る。まず、微量の酸素が存在し得る環境下での酸化反応 は、下記式(1)の様になり、 $\mathrm{Sn}$ が酸化物 $\left(\mathrm{SnO}_{2}\right)$ となる ことで金属 $\mathrm{Cu}$ が生じる。

$$
\mathrm{Cu}_{3} \mathrm{Sn}+\mathrm{O}_{2} \rightarrow \mathrm{SnO}_{2}+3 \mathrm{Cu}
$$

これに対して、酸素供給量を 2 倍弱に増やした場合は、 $\mathrm{Sn}$ が同様に酸化物 $\left(\mathrm{SnO}_{2}\right)$ として分離し、 $\mathrm{Cu}$ は亜酸化 銅 $\left(\mathrm{Cu}_{2} \mathrm{O}\right)$ になると推定される。

$$
\mathrm{Cu}_{3} \mathrm{Sn}+(7 / 4) \mathrm{O}_{2} \rightarrow \mathrm{SnO}_{2}+(3 / 2) \mathrm{Cu}_{2} \mathrm{O}
$$

さらに、酸化供給量を増加させた場合は、Sn と共に $\mathrm{Cu}$ も安定な酸化銅（ $\mathrm{CuO} ）$ になると推定される。

$$
\mathrm{Cu}_{3} \mathrm{Sn}+(5 / 2) \mathrm{O}_{2} \rightarrow \mathrm{SnO}_{2}+3 \mathrm{CuO}
$$

この $\mathrm{CuO}$ は、硫酸に浸出し易い状態であるため、硫酸 浸出時に高い浸出率となることが期待できる。 


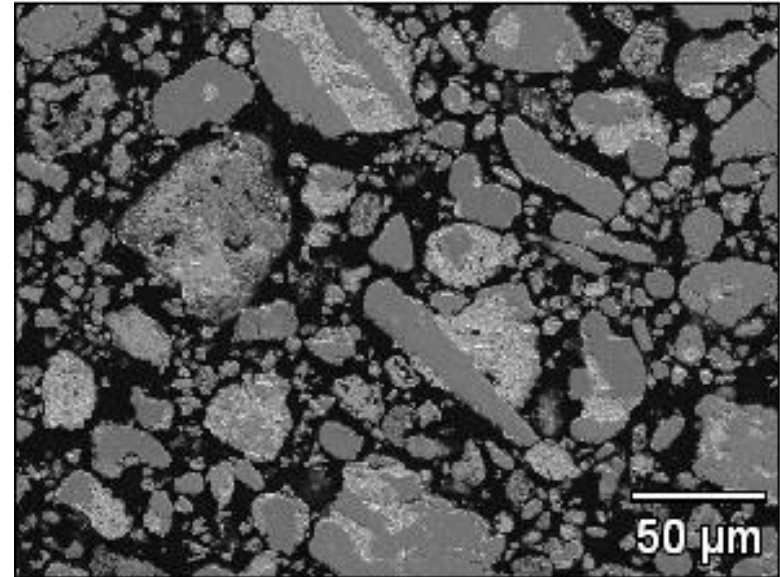

Fig.1-1. SE image for $\mathrm{Cu}$-compound of raw material.

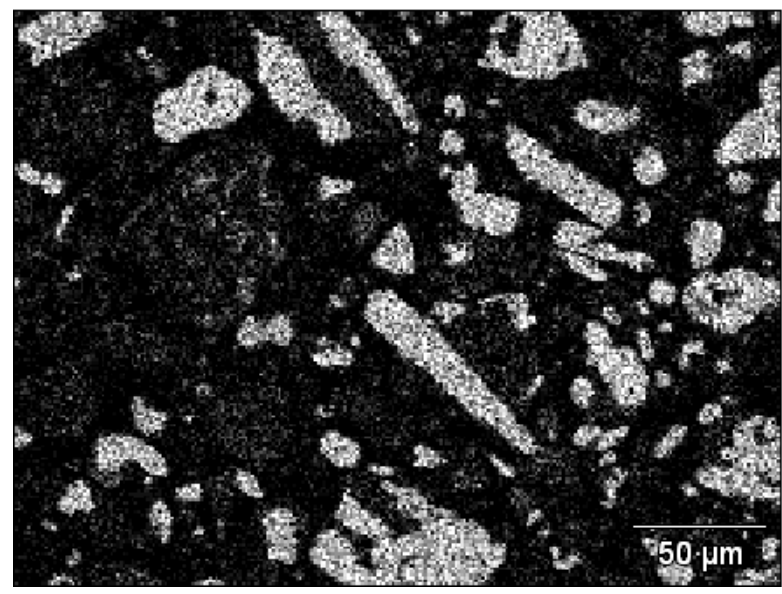

Fig.1-2. Cu X-ray image for $\mathrm{Cu}$-compound of raw material by EDS peak deconvolution map.

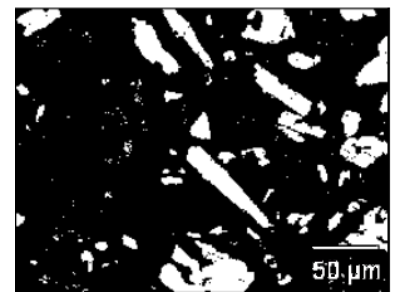

a)

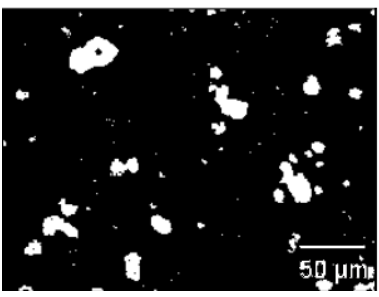

b)
Fig.1-3. $\mathrm{Cu}$ alloys for principal component maps by COMPASS, a) $\mathrm{Cu}_{3} \mathrm{Sn}$ and b) $\mathrm{Cu}_{3}$ As .

原料試料を酸化させるためには、熱処理炉を用いて気 相酸化させることが、最も低コストで実現可能である。 また、炉内の酸素量は、炉の大気導入口の開閉により容 易に可能であることから、今研究においては、炉内の酸 素供給量が及ぼす $\mathrm{Cu}$ の存在状態への影響について、大 気導入口の開閉割合を制御することで検討を行った。以 下に、原料試料をそれぞれ酸化状態の異なる条件におい

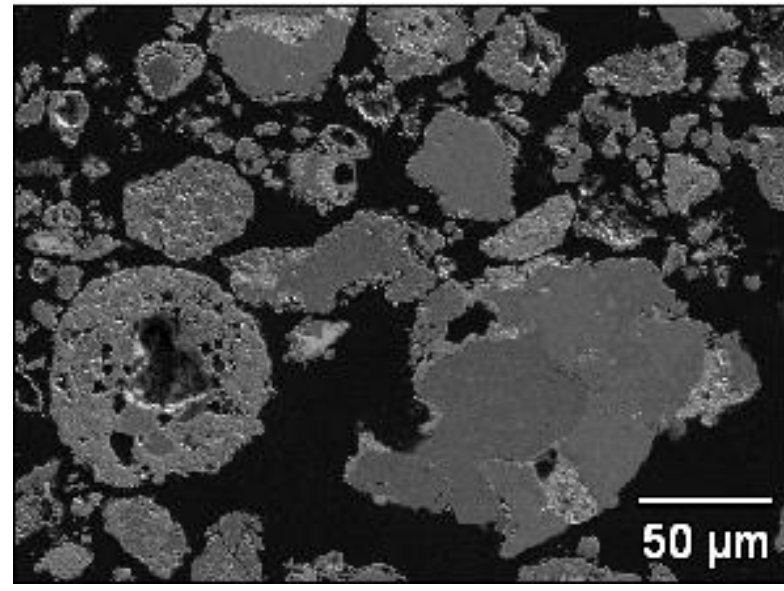

Fig.2-1. SE image for Cu-compound of closed heat treatment process.

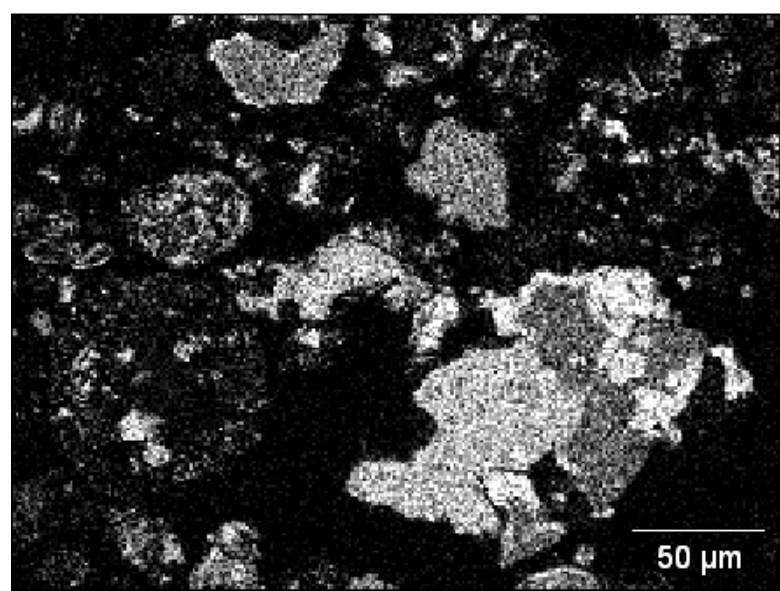

Fig.2-2. Cu X-ray image for $\mathrm{Cu}$-compound of closed heat treatment process by EDS peak deconvolution map.

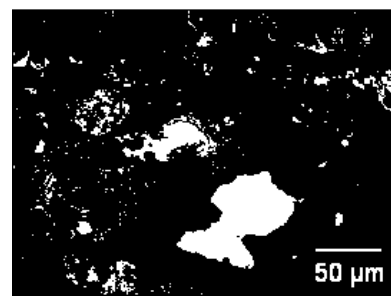

a)

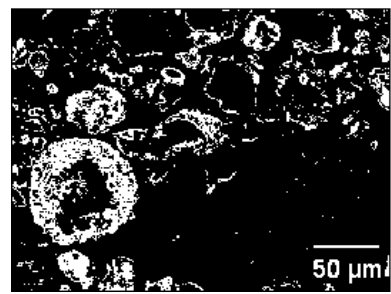

c)

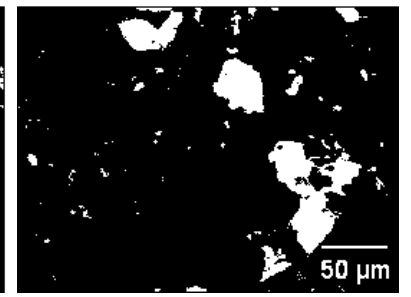

b)

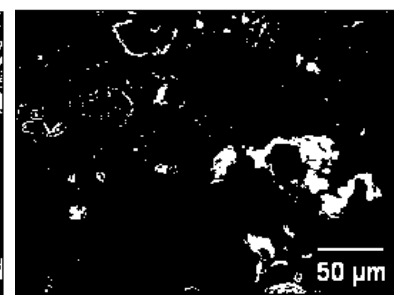

d)
Fig.2-3. $\mathrm{Cu}$ alloys for principal component maps by COMPASS, a) $\mathrm{Cu}_{2} \mathrm{~S}$, b) $\left.(\mathrm{Cu}, \mathrm{Ni})_{3}(\mathrm{As}, \mathrm{Sb}), \mathrm{c}\right) \mathrm{Cu}-\mathrm{Sn}-\mathrm{O}$ and d) Metal-Cu. 


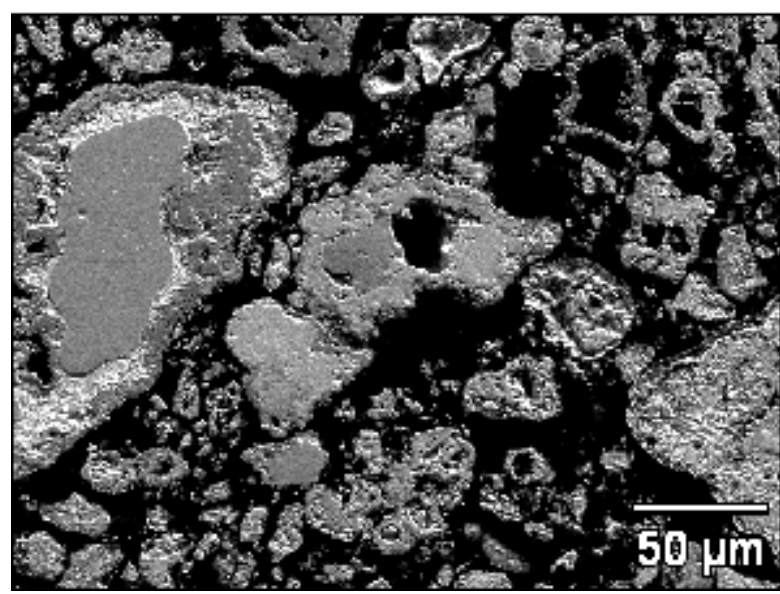

Fig.3-1. SE image for Cu-compound of $100 \%$ opened heat treatment process.

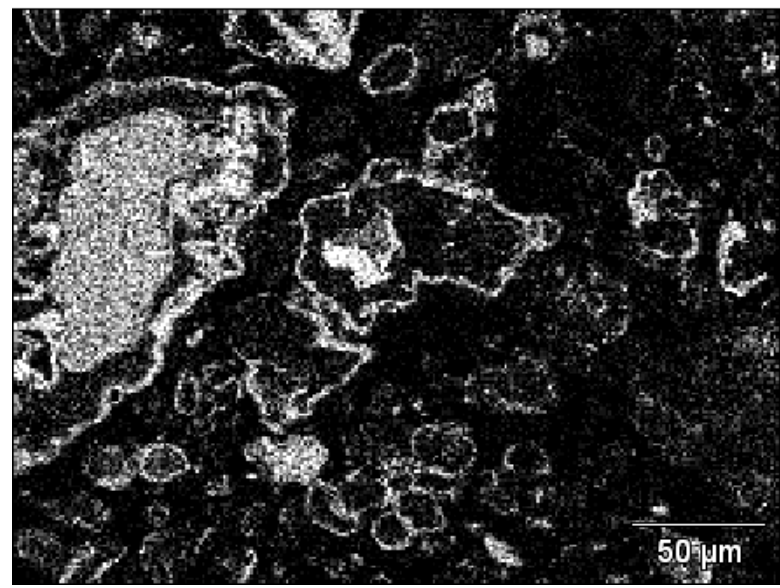

Fig.3-2. Cu X-ray image for Cu-compound of $100 \%$ opened heat treatment process by EDS peak deconvolution map.

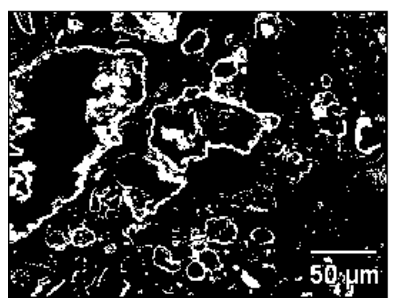

a)

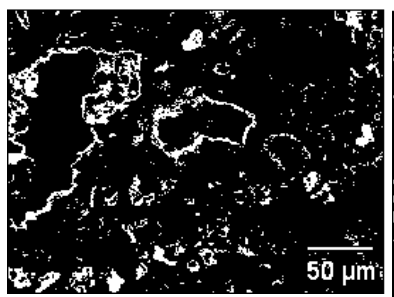

c)

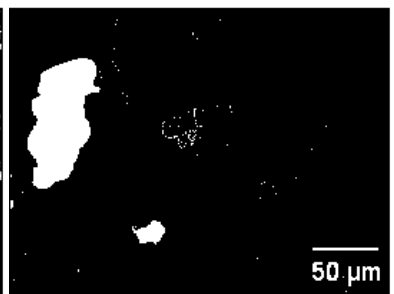

b)

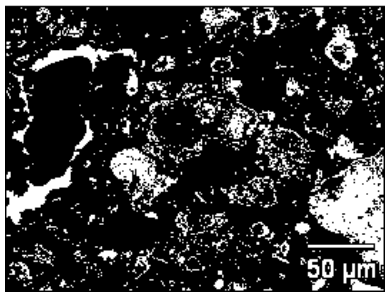

d)
Fig.3-3. $\mathrm{Cu}$ alloys for principal component maps by COMPASS, a) $\mathrm{CuO}$, b) $\mathrm{Cu}_{3} \mathrm{Sb}$, c) $\mathrm{SnO}_{2}$ and d) $\mathrm{PbO}_{2}$.
て熱処理し、自動相分離解析から得られた $\mathrm{Cu}$ の存在形 態を中心に述べる。

まず、ドラム炉中に原料試料の含銅ドロスを投入し、 大気導入口を閉じて熱処理を行った。この際内部は、原 料を投入した際に含まれる炉内空気中の酸素のみで、蒸 し焼き状態にあると推定される。このように処理した後 の試料について、原料試料と同様に自動相分離解析を実 施した（Fig.2）。この結果から、Cu が帰属する主成分相 は、 $\mathrm{Cu}_{2} \mathrm{~S} 、 \mathrm{Cu}-\mathrm{Sn}$ 複合酸化物、 $(\mathrm{Cu}, \mathrm{Ni})_{3}(\mathrm{As}, \mathrm{Sb})$ および金属 $\mathrm{Cu}$ であった。

$\mathrm{Cu}$ の存在形態については、一部が $\mathrm{Cu}$ と $\mathrm{Sn}$ の複合酸 化物となっているが、式(1)の様に $\mathrm{Cu}_{3} \mathrm{Sn}$ から一部が金属 $\mathrm{Cu}$ として分離しており、 $\mathrm{Cu}$ を酸化するには酸素量が不 十分であったことが解る。また、原料試料に多く含まれ ていた $\mathrm{PbS}$ の影響で、 $\mathrm{Cu}$ のほとんどは $\mathrm{Cu}_{2} \mathrm{~S}$ を形成して いたことが解った。

次に、大気導入口を 60\%開口して熱処理を行った際の 自動相分離解析結果を Fig.3 に示す。第 1 主成分は $\mathrm{PbO}_{2}$ であったが、 $\mathrm{PbO}_{2}$ を覆う様に $\mathrm{SnO}_{2}$ が分布し、さらにそ れらを覆うように $\mathrm{CuO}$ が存在していた。また $\mathrm{Cu}$ につい ては、一部 $\mathrm{Cu}_{3} \mathrm{Sb}$ （Ni，As もわずかに含有）として存在 していた。この結果から、大量に大気が供給される状況 下における気相酸化反応下では、式(3)の反応が進行し、 $\mathrm{Cu}$ は酸化物として安定な $\mathrm{CuO}$ となり、試料の表面に分 布していることが明らかになった。

最後に、原料試料である含銅ドロスを含め、大気供給 量を調節して気相酸化反応を実施した各試料を硫酸浸出 させ、浸出せずに沈殿した残椬の重量から浸出率を求め た（Fig.4）。この結果から、原料試料では 50\%の浸出率 を示していたものの、大気導入口を閉口して熱処理を行 った際には、5\%に減少していた。これは、Fig.2 にある ように $\mathrm{Cu}$ の主な存在形態がが硫化物であるためと推定 できる。これに対して、大気導入口を $60 \%$ で熱処理を行 った試料については、 $\mathrm{Cu}$ に加え $\mathrm{Sn}, \mathrm{Pb}$ 共に酸化物とな っているので、95\%と高い浸出率を実現したと推定され る。

これらの結果から、含銅ドロスを効率的に浸出させる には、積極的に酸化を行うことが非常に有効であること が解った。

以上の様に、SDD-EDS と多変量イメージ解析技術を組 み合わせた評価技術を用いて、気相酸化熱処理工程時に おける酸素供給量が及ぼす処理後の銅の存在状態を把握 することで、含銅ドロスの反応機構を解明することがで き、 $\mathrm{Cu}$ 化合物の製錬効率を向上させ、各元素の高純度化 を達成するための方針が明らかにできた。 


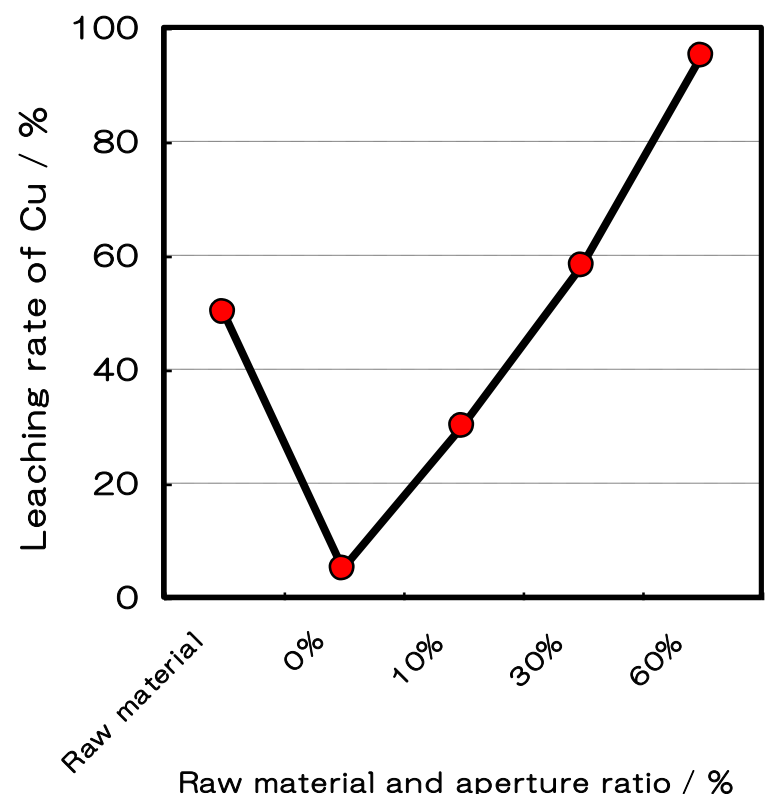

Fig. 4. Effect of heat treatment process on leaching rate of $\mathrm{Cu}$.

今回は、硫酸浸出における浸出率に関して調査検討を 実施したが、製鍊工程によってはアンモニア浸出を行う 場合もある。硫酸浸出とアンモニア浸出では、同じ試料 を処理しても浸出率に大きな違いが出るため、今回の結 果を元に、アンモニア浸出残椬などを評価することで、 より高い浸出率が得られる前処理条件が解明可能である と予想する。また、今回の硫酸浸出残椬についてもさら に自動相分離解析を実施することで、更なる浸出率の向 上が図れると期待できる。

\section{CONCLUSION}

自動相分離解析（多変量イメージ解析ソフトウェア： COMPASS）による主成分相解析の結果、ドロス中の銅
化合物は熱処理中の酸素導入量が極わずかな場合、硫化 銅を主に形成した。これに対して、酸素供給量を極めて 多くした熱処理条件の下では、 $\mathrm{CuO}$ が主成分であること が明らかになった。

また、硫酸浸析後の銅の回収率は、未処理ドロスは $50 \%$ 程度であったが、 $\mathrm{CuO}$ が主成分となった場合は $95 \%$ の回 収率を得られた。

これらの結果から、銅製錬工程において効率的(容易、 短時間、低コスト）に銅を回収するために必要となる、 気相酸化処理の反応機構（プロセス）を解明できた。

\section{ACKNOWLEDGEMENTS}

本研究を遂行するにあたり、SDD-EDS 検出器 (Ultra-Dry) と、多変量イメージ解析ソフトウェア (COMPASS) での自動相分離解析に関して御協力賜り ました、サーモフィッシャーサイエンティフィック株式 会社鈴木様に深く感謝いたします。

また、本実験の遂行に当たり多大な御協力を賜りまし た、三井金属鉱業株式会社金属・環境事業本部古田様、 ならびに舘田様に深く感謝いたします。

\section{REFERENCES}

${ }^{1} \mathrm{~W}$. Yan and W. L. Cai, Huagong Yejin, 213 , 298-301 (2000).

${ }^{2}$ W. Yan, Huagong Yejin, 21 4, 403-406 (2000).

${ }^{3}$ T. deng and Z. Wen, Huagong Yejin, 21 3, 236-240 (2000).

${ }^{4}$ K. Tozawa, Y. Sugawara, Y. Umetsu and B. Ogiso, Bulletin of the Research Institute of Mineral Dressing and Metallurgy, Tohoku University 31(1), 16-26 (1975).

5 M. Wada, J. Adv. Sci., 22, 1-6 (2010). 